\title{
One-size MAP does not fit all
}

\author{
Mourad H Senussi
}

\section{One-size mean arterial pressure does not fit all}

The Surviving Sepsis Campaign [1] advocates maintaining a mean arterial pressure (MAP) of at least $65 \mathrm{~mm} \mathrm{Hg}$ in sepsis patients undergoing resuscitation. Leone and colleagues [2], in an article published in this journal, suggest considering higher MAP targets in the resuscitation of patients with a history of arterial hypertension so they do not progress to acute kidney injury. Asfar and colleagues [3], in a multicenter, open-label trial, showed no significant difference in mortality outcomes in septic shock patients undergoing resuscitation with an MAP target of either 80 to $85 \mathrm{~mm} \mathrm{Hg}$ (high-target group) or 65 to $70 \mathrm{~mm} \mathrm{Hg}$ (low-target group). However, the study did show that chronic hypertensive patients in the higher-target group had lower incidences of acute kidney injury and renal replacement therapy. This likely stems from the need for higher MAPs in chronic hypertensive patients in order to maintain organ blood flow because of a shift of the organ's autoregulatory range to the right. Thus, targeting a higher MAP for chronic hypertensive patients may help avoid the development of acute kidney injury and the need for renal replacement therapy. Renal replacement therapy carries with it inherent morbidity as well as additional cost. These costs include the need for dialysate fluid and extra personnel and the use of anticoagulation and the extracorporeal circuit [2]. However, chronic hypertensive patients in the high-target group had a greater incidence of new-onset atrial fibrillation $(5.2 \%$ in the low-target group versus $9 \%$ in the high-target group). Patients with new-onset atrial fibrillation during sepsis have been shown to have increased incidences of in-hospital stroke and in-hospital mortality [4] as well as subsequent recurrence of atrial fibrillation and increased long-term risks for heart failure, ischemic stroke, and death [5]. This may offset any benefit of a higher MAP. The ideal target MAP may have to be individualized for specific patient populations. More studies are needed to determine whether baseline blood pressure plays a role in the ultimate determination of the ideal MAP target for patients with sepsis.

\begin{abstract}
Abbreviation
MAP: Mean arterial pressure.
\end{abstract}

\section{Competing interests}

The author declares that he has no competing interests.

Published online: 07 May 2015

\section{References}

1. Dellinger RP, Levy MM, Rhodes A, Annane D, Gerlach H, Opal SM, et al. Surviving sepsis campaign: international guidelines for management of severe sepsis and septic shock: 2012. Crit Care Med. 2013:41:580-637.

2. Leone M, Asfar P, Radermacher P, Vincent J-L, Martin C. Optimizing mean arterial pressure in septic shock: a critical reappraisal of the literature. Crit Care. 2015;19:794.

3. Asfar P, Meziani F, Hamel J-F, Grelon F, Megarbane B, Anguel N, et al. High versus low blood-pressure target in patients with septic shock. N Engl J Med. 2014;370:1583-93.

4. Walkey AJ, Wiener RS, Ghobrial JM, Curtis LH, Benjamin EJ. Incident stroke and mortality associated with new-onset atrial fibrillation in patients hospitalized with severe sepsis. JAMA. 2011;306:2248-54.

5. Walkey AJ, Hammill BG, Curtis LH, Benjamin EJ. Long-term outcomes following development of new-onset atrial fibrillation during sepsis. Chest. 2014;146:1187-95. 